\title{
ENTREVISTA
}

\section{ENTREVISTA COM A PSICÓLOGA E SEXÓLOGA ANA CANOSA}

\author{
por Sheila Reis
}

Ana Canosa, é psicóloga, especialista em Educação Sexual e Terapia Sexual pela Faculdade de Medicina do ABC e Sociedade Brasileira de Estudos em Sexualidade Humana (FMABC/SBRASH). Coordenadora e docente do curso de PósGraduação em Educação em Sexualidade e Terapia Sexual do Centro Universitário Salesiano (UNISAL). Diretora de publicação da Revista Brasileira de Sexualidade Humana, um periódico científico da SBRASH.

\section{Conte-nos um pouco sobre você.}

Fiz muitos anos de psicoterapia junguiana, linha teórica que adoro, embora não a adote como ferramenta no meu atendimento clínico. Minha terapeuta me dizia que eu era do tipo "intuitiva" e essa tipificação foi fazendo sentido para mim, principalmente quando olho para trás e revejo minha trajetória. Nem a Psicologia e nem a Sexologia eram ideias claras; meu interesse pelo psiquismo e seus desdobramentos me acompanhava na relação com as pessoas à minha volta, nos temas que circulavam, nos por quês, nas inquietações, nas descobertas. As coisas foram "acontecendo" de maneira "orgânica". Entrei na faculdade sem saber ao certo se era $O$ curso e me descobri psicóloga. Foi assim com a sexologia também. Meu amigo, colega e ginecologista Eliezer Berenstein fazia parte da coordenação do primeiro curso de Educação Sexual em São Paulo, promovido pela SBRASH e Faculdade de Medicina do ABC, em 1994. Em uma consulta de rotina ele me disse que eu devia fazer o curso, que era "a minha cara". Entrei na especialização e me apaixonei. $E$ foi nesse mesmo curso que eu comecei a dar aulas, passei a coordenadora, entrei como associada na SBRASH, assumi a Revista Brasileira de Sexualidade Humana e a minha vida profissional se desenvolveu, tanto na esfera acadêmica, quanto na clínica. Fiz muitos amigos, como Ronaldo Zacharias, com quem hoje divido a coordenação de um curso de Pós-Graduação em Sexualidade no UNISAL, além de ter vivido muitos anos ao lado do Dr. Nelson Vitiello, um dos fundadores da SBRASH, talvez o maior responsável pela propagação da entidade no Brasil. Devo a ele as oportunidades que me ofereceu, a descoberta fundamental da minha carreira, que é ser comunicadora, o que me possibilitou desenvolver várias atividades profissionais diferentes, como ser professora, escrever, além do consultório e das participações na TV. Tipicamente geminiana, com a sorte de ter descoberto muito cedo minhas habilidades e aptidões. Percebi que as pessoas sempre souberam de mim, antes de mim, o que faz todo o sentido para quem usa a comunicação como a sua maior ferramenta de trabalho. Sou uma profissional satisfeita e feliz.

Como diretora de publicação, nas últimas duas décadas da Revista da Sociedade Brasileira de Estudos em Sexualidade Humana, o que a motiva nesse cargo?

Quando o Nelson Vitiello me chamou para ser editora e ajudá-lo com a Revista, eu era crua de tudo. De novo aconteceu o processo: ele via em mim alguém que poderia se comprometer com o desafio de organizar a Revista, editar, corrigir, crescer em conjunto com as atividades acadêmicas que estavam começando no país nessa área. E lá fui eu me descobrir. A Revista sempre foi a minha atividade profissional mais difícil, mais desafiadora e a mais frustrante também. Sim, porque até esse ano de 2018 ela só era destinada aos associados e às bibliotecas, o que a limitava como periódico científico. Não conseguimos acompanhar o crescimento dos periódicos porque a SBRASH passou por diversos momentos difíceis; não havia possibilidade de investimento para torná-la uma revista aberta, em plataforma própria, seguindo critérios mais rígidos de indexação. A Revista sempre foi feita com dinheiro da SBRASH, destinado à sua revisão e formatação, todo o resto eu fiz de maneira voluntária, com a ajuda dos editores associados e do conselho editorial na avaliação dos artigos. Sempre deu muito trabalho, intelectual e braçal, receber artigos, encaminhar, avaliar, fazer revisão, montar a revista em arquivo, rever a diagramação, enviar aos associados. Muitas vezes eu pensei em desistir, principalmente nos momentos em que a Revista ficou atrasada. Chegamos a ter quase dois anos de atraso na publicação, uma frustração sem tamanho! Sem a parceria dos diretores e associados, nas últimas duas gestões, não teríamos conseguido chegar a 2018 com um 
número publicado em 2018, menos ainda ter decidido investir para que ela finalmente cresça como um periódico científico importante, pelo caráter multidisciplinar e abrangência nacional. Finalmente conseguimos contratar uma assessoria específica nessa área, que está implementando o sistema Open Journal System (OJS), desenvolvido para a criação e gestão de periódicos eletrônicos na University of British Columbia pelo Public Knowledge Project. O OJS foi customizado pelo Instituto Brasileiro de Informação em Ciência e Tecnologia (IBICT) e vem sendo amplamente utilizado pela comunidade científica brasileira há mais de dez anos. A utilização desse software permitirá maior agilidade no processo editorial e facilitará a adoção de padrões internacionais e a disseminação e preservação do conteúdo.

Sempre acreditei na SBRASH e pelos anos de compromisso com a entidade já fui solicitada várias vezes a assumir como candidata à presidência, no que sempre recusei, por achar que pelos anos de trabalho com a Revista eu seria melhor aproveitada na diretoria de publicação. A cada eleição, eu sempre disponibilizo meu cargo como editora, para dar possibilidade para outras pessoas, mas até hoje ninguém se candidatou. Agora que o trabalho braçal acabou, nem cheguem perto (rsrs)! Nos próximos anos quero desfrutar de seu crescimento, vê-la florir!

No novo site' podem ser encontradas as edições de 2017 e 2018. As edições anteriores continuarão sendo acessadas pela página da Sociedade Brasileira de Estudos em Sexualidade Humana. A RBSH informa que as submissões, a partir de agora, devem ser feitas através da nova plataforma e todo o processo editorial poderá ser acompanhado pelo autor.

Após esses $\mathbf{2 8}$ anos de atuação profissional, em diversas áreas da sexualidade (clínica, educacional e na mídia em geral), quais as dificuldades ainda enfrentadas?

Felizmente acompanhei o desenvolvimento da sexologia brasileira, tanto na esfera clínica, quanto educacional e social. Avançamos muito. Hoje temos uma profusão de profissionais formados, a sexualidade é pauta para todo tipo de abordagem na mídia e muitos educadores conseguem construir um diálogo com seus alunos, ampliando a discussão para além do corpo reprodutivo e Infecções Sexualmente Transmissíveis (ISTs). Percebo como é difícil falar de prazer sexual no âmbito educativo, como se sexo fosse só doença e gravidez indesejada. Esse é um avanço que os educadores precisam enfrentar e discutir. Não há satisfação maior que ver meus alunos trabalhando com a temática, ajudando tantas pessoas. Tenho uma ex-aluna da pós que é contratada como educadora em sexualidade em uma escola particular de São Paulo. O que me entristece é ver o trabalho da educação em sexualidade deturpado e usado como ferramenta política, na tentativa de conter avanços na luta pela discussão de gênero e da diversidade sexual. Mas estamos atentos para garantir que os direitos constitucionais sejam preservados e lutar contra retrocessos. Além disso, a sexualidade não é compreendida por muitos como um campo primordial para investimento em pesquisa em todas as suas dimensões. O Brasil ainda precisa caminhar muito nesse sentido.

Na maioria das faculdades de Psicologia, entre outros cursos da área da saúde, não há a disciplina Sexualidade Humana, nem como disciplina eletiva. Como fica a formação desse futuro profissional, principalmente com o tema sendo muito mais discutido pela mídia? Há também, uma escassez de cursos de especialização na área da Sexualidade Humana. O que você pode orientar aos profissionais que queiram seguir nesse estudo e formação?

Penso que o curso de Psicologia deveria repensar o currículo e dar especial importância às relações afetivas e à sexualidade. É sem dúvida uma lacuna enorme, pois os profissionais saem da faculdade com pouca ou quase nenhuma formação em terapia sexual, tampouco em dinâmicas relacionais, como a terapia de casal. Nós que trabalhamos com esse tema, sabemos como ele é fonte ou/e resultado de conflitos intrapsíquicos e inter-relacionais. Os cursos de especialização em sexualidade vêm suprir essa demanda, mas mesmo eles têm sofrido com o momento político-econômico do país; muitos não conseguem "sobreviver". Além disso, não há mecanismos regulatórios garantindo a qualidade das especializações. A profissão do terapeuta sexual, no Brasil, é "terra de ninguém", pois não tem regulação pelo Conselho Federal de Psicologia (CFP). Penso que primeiro o CFP deveria nos ajudar com esse diálogo: seria a terapia sexual uma ferramenta exclusiva do psicólogo? Como diferenciar o profissional da Psicologia especialista em sexualidade de outros profissionais que também fazem uso de técnicas para tratamento de disfunções sexuais? Penso que uma discussão dessa natureza poderia refletir na revisão dos currículos dos cursos de Psicologia. Além disso, a UNESCO já orientou a inserção da disciplina sexualidade em todas as licenciaturas. Nos últimos dois anos o UNISAL fez um movimento grande, pensando as ementas e incorporando a disciplina sexualidade em todas as licenciaturas, uma iniciativa sem precedentes. Estamos muito orgulhosos por termos dado esse passo. Mas não conheço outra universidade que tenha feito isso. Dá para contar nos dedos aquelas que introduziram uma disciplina de sexualidade na

' O novo site da Revista pode ser acessado através do link: https://revista.sbrash.org.br/index.php/revista_sbrash. 
formação de educadores, médicos e psicólogos. Então, os profissionais que desejam seguir a formação em sexologia, terão de lançar mão das especializações, ficar perto de associações como a SBRASH, participar dos eventos que acontecem durante $\mathrm{o}$ ano inteiro, em diversos locais do país, promovidos por ONGs, secretarias de saúde, educação e cultura, universidades, coletivos, associações etc. Tem muita gente boa produzindo conteúdo de qualidade, promovendo reflexões, disseminando conhecimento. Mas atenção também para os que usam a sua vida pessoal como régua para o ensino, que se autointitulam especialistas e saem por aí divulgando material e conteúdo sem fundamento teórico nenhum. Estou cansada de receber artigos, na Revista, nos quais a pessoa coloca que "estudos apontam", sem citar uma referência bibliográfica sequer, manipulando o discurso em prol de suas hipóteses, para provar teorias bem particulares. É preciso estar atento.

\section{Sexualidade Humana por Ana Canosa:}

a dimensão da vida mais divertida e apaixonante.

Rio de Janeiro, 10 de junho de 2018.

Sheila Reis

Psicóloga e mestre em Sexologia

Vice-presidente da SBRASH - biênio 2018/19 